\title{
Differential actions of acute and chronic citalopram on the rodent hypothalamic-pituitary-adrenal axis response to acute restraint stress
}

\author{
S Hesketh, D S Jessop, S Hogg ${ }^{1}$ and M S Harbuz \\ University of Bristol, HWLINE, Dorothy Hodgkin Building, Whitson Street, Bristol, BS1 3NY, UK \\ ${ }^{1}$ Department of Pyschopharmacology, H Lundbeck A/S, Copenhagen, Denmark \\ (Requests for offprints should be addressed to M S Harbuz; Email: m.s.harbuz@bristol.ac.uk)
}

\begin{abstract}
Serotonin re-uptake inhibitors (SSRIs) can affect the basal activity of the hypothalamic-pituitary-adrenal (HPA) axis in rats. A single injection of citalopram has been shown to stimulate the HPA axis while repeated administration leads to attenuation of the corticosterone response to the SSRI. The purpose of this work was to investigate the rodent HPA axis response to restraint stress, following acute and chronic treatment with the SSRI citalopram. We have demonstrated that a single injection of citalopram is able to prolong acute restraint-induced increases in plasma levels of corticosterone and adrenocorticotrophin (ACTH). This is possibly mediated by arginine vasopressin (AVP) in the parvocellular cells of the paraventricular nucleus (pPVN), as treatment with citalopram or restraint alone did not increase AVP mRNA in pPVN while the combination of treatments resulted in a significant increase in AVP mRNA in the pPVN. In contrast, the increase in corticotrophin-releasing factor (CRF) mRNA in the pPVN in response to acute restraint stress was not altered by citalopram. Oxytocin (OT) mRNA was also increased in the magnocellular PVN (mPVN) by the solo treatments
\end{abstract}

of citalopram and restraint, and was not further enhanced by the dual treatment of restraint and citalopram. Chronic treatment with citalopram did not alter basal plasma levels of corticosterone or ACTH. However, the ACTH response to acute restraint was attenuated following chronic citalopram treatment. AVP mRNA in the pPVN was significantly elevated in response to chronic citalopram compared with saline controls suggesting an effect mediated through the AVP subset of pPVN neurones. The CRF mRNA response to acute restraint was not altered in rats treated chronically with citalopram. OT mRNA was not enhanced in the mPVN following chronic infusion of citalopram but was increased by acute restraint stress. We conclude from these data that both acute and chronic citalopram treatment has the potential to alter the rodent response to acute restraint stress. These effects appear to be regulated by the AVP-containing subset of CRF neurons in the pPVN and thus suggest that parvocellular AVP may have an important role in mediating the actions of SSRIs. Journal of Endocrinology (2005) 185, 373-382

\section{Introduction}

The hypothalamic-pituitary-adrenal (HPA) axis serves as a neuroendocrine stress response system, which has an important role in the maintenance of homeostatsis (Buckingham et al. 1997). Stimulation of the HPA axis results in the release of glucocorticoids from the adrenal cortex. Glucocorticoids can initiate negative feedback pathways to minimize long term activation of the HPA axis, induced in response to a stressor (Reul \& De Kloet 1985, Ratka et al. 1989, Dallman et al. 1991, Young \& Vazquez 1996, De Kloet et al. 1998). The HPA axis is regulated at the central level by the paraventricular nucleus (PVN). The PVN is able to coordinate and respond to a variety of stimuli including immune, psychological and physical challenges (Herman et al. 2002).
Within the PVN, magnocellular (mPVN) and parvocellular (pPVN) regions (Swanson \& Sawchenko 1983) produce peptides involved in the stress response. Parvocellular derived corticotrophin releasing factor (CRF) and arginine vasopressin (AVP) peptides are involved in the release of adrenocorticotrophic hormone (ACTH) from the anterior pituitary. There are two major subsets of CRF neurons in the pPVN; those containing CRF alone and those containing CRF and AVP (Whitnall \& Gainer 1988).

CRF is the main hypothalamic peptide involved in the release of ACTH from the anterior pituitary (Aguilera 1994). AVP is a weak solo stimulator of ACTH release that can synergistically enhance the actions of CRF upon ACTH release from pituitary corticotrophs (Gillies et al. 1982). However, under chronic stress conditions it has 
been proposed that AVP can become the major stimulator of the HPA axis and may be important in maintaining the stress response when the pituitary is refractory to CRF (Scaccianoce et al. 1991, Chowdrey et al. 1995, Aguilera \& Rabadan-Diehl 2000, Harbuz 2002). Oxytocin (OT) is another peptide produced mainly within the mPVN (Swanson \& Sawchenko 1983), but also within the pPVN, that may have a role in the mediation of the stress response (Neumann et al. 2000a,b, Nakashima et al. 2002, Neumann 2002).

Restraint stress is a well documented predominantly psychological stressor (Pare \& Glavin 1986, Harbuz \& Lightman 1992, Harbuz et al. 1993), that acutely initiates a transient increase in plasma ACTH and corticosterone (the major glucocorticoid in rodents), usually peaking during the course of a $60 \mathrm{~min}$ stress exposure. CRF mRNA in the pPVN also increases, at around 3-4 h after the start of stress (Harbuz \& Lightman 1989). Within $60 \mathrm{~min}$ following the termination of a $60 \mathrm{~min}$ restraint stress, plasma levels of corticosterone and ACTH are restored to basal levels and CRF mRNA expression in the PVN gradually returns to basal levels (Harbuz \& Lightman 1989). Parvocellular AVP mRNA can also be increased by acute immobilisation stress (Aubury et al. 1999) although such increases do appear to be strain and procedure dependent (Harbuz et al. 1994).

There is a putative role for central serotonin in the coordination of the HPA axis activity under basal and stressed conditions (Dinan 1996, Matheson et al. 1997, Jorgensen et al. 1998, Chaouloff 2000, Jorgensen et al. 2002). Furthermore serotonergic dysfunction is also associated with depression and around 50\% of patients diagnosed with depression have hypercortisolaemia and thus have altered basal HPA axis activity (Gibbons 1964, Nemeroff et al. 1984, Young et al. 1991, Graeff et al. 1996, Arborelius et al. 1999, Hatzinger 2000). Whether hypercortisolaemia is a cause or a consequence of depression remains to be determined. However, impaired feedback responses are considered responsible for the HPA axis overdrive in depression (Young et al. 1991). Selective serotonin re-uptake inhibitors (SSRIs) are the drugs of choice for the treatment of depression. SSRIs block the re-uptake activity of the serotonergic transporter leading to an initial increase in synaptic levels of serotonin following acute administration and modulation of serotonergic activity following chronic (repeated) administration (Massand \& Gupta 1999, Davis et al. 1999). SSRI treatment can alter activity of the HPA axis (Jensen et al. 1999, 2001, Raap \& Van de Kar 1999, Wieczorek et al. 2001). Citalopram and fluoxetine have been shown to acutely stimulate the rodent HPA axis while this stimulation is attenuated in chronically citalopram-treated rats (Jensen et al. 1999, 2001). It is thought that SSRIs may normalize the basal hyperactive HPA axis in depression, possibly via re-establishment of the feedback control (De Bellis et al. 1993, Maes et al. 1995, Raap \& Van de Kar 1999) via the increase in mineralocorticoid receptor levels principally in the hippocampus (Pariante et al. 2004). The HPA axis may be an important target for SSRI-induced clinical improvement in patients diagnosed with depression and who demonstrate hyper-cortisol secretion. However, there is little data available on how SSRI treatment may affect HPA axis responsiveness. Given the wide use of SSRI's in psychiatry, a better understanding of HPA responsiveness and function following exposure to SSRI's, may provide an improved knowledge of how SSRI's may contribute to clinical improvement in various patients. The purpose of these studies was to evaluate the rodent HPA response to acute restraint stress, following acute and chronic treatment with citalopram so as to better understand how a mammalian system may respond to a psychological stressor in the presence of SSRI's.

\section{Materials and Methods}

\section{Animals}

Adult male Sprague-Dawley rats (Harlan-Olac, Bicester, UK) weighing 200-250 g, were initially housed four to a cage. Following implantation of i.v. and s.c. cannulae rats were assigned to individual cages. Rats had free access to pellet diet and water and were maintained on a $12 \mathrm{~h}: 12 \mathrm{~h}$ light:dark cycle with lights on at $0600 \mathrm{~h}$. The room temperature was $21{ }^{\circ} \mathrm{C}$. Studies were commenced at $0830 \mathrm{~h}$. All procedures carried out were in accordance with the Animals (Scientific Procedures) Act 1986.

\section{Drugs}

Citalopram (gift from $\mathrm{H}$ Lundbeck A/S, Copenhagen, Denmark) was made up in $0.9 \%$ sterile saline (vehicle). Other reagents: heparin-saline solution (made up as 50 units $/ \mathrm{ml})$; Hypnorm $(0.315 \mathrm{mg}$ fentyal and $10 \mathrm{mg}$ fluranisone $/ \mathrm{ml}$ (Janssen Pharmaceutica, UK); $100 \mu \mathrm{l} /$ $250 \mathrm{~g}$ intramuscular (i.m.) injection); Diazepam (1 mg/ml, (Sigma-Aldrich) $250 \mu \mathrm{l} / 250 \mathrm{~g}$ i.p. injection). Halothane (2-4\% gas (INEOS Fluor, Cheshire, UK)).

\section{Surgery}

An i.v. cannula for the collection of blood and a s.c. cannula for the administration of citalopram or vehicle were implanted into rats under Hypnorm-Diazepam anaesthesia. Animals were allowed four recovery days following surgery prior to carrying out the experimental protocol.

The Alzet osmotic minipumps held a total volume of $2 \mathrm{ml}$ released over 14 days at $5 \mu \mathrm{l} / \mathrm{h}$, and were filled with either citalopram $(10 \mathrm{mg} / \mathrm{kg} /$ day based on a mid experiment weight of rats $\sim 250 \mathrm{~g})$ or vehicle solution $(0.9 \%$ sterile saline). Minipumps were prepared and stored in 
sterile saline solution for $12 \mathrm{~h}$ prior to surgery. Animals were briefly anaesthetized using halothane gas anaesthesia and minipumps were implanted into the dorsal s.c. space. Once recovered, rodents were returned to their home cages and checked every second day.

\section{Experiment 1: a single dose of citalopram and acute restraint stress}

A cannula was implanted into each rat on day 0 , and on day 4 an initial blood sample $(300 \mu \mathrm{l})$ was collected from all rats through the i.v. cannula (zero minute blood sample). Immediately after collection of this basal sample, citalopram or vehicle were administered through the s.c. cannula and half of the citalopram treated rats and half of the vehicle treated rats were restrained for $60 \mathrm{~min}$ in clear plastic circular restrainers $(10 \mathrm{~cm}$ in length by $6 \mathrm{~cm}$ diameter - these allowed small forward and reverse movements but no rotation). The remaining rats were kept in their home cages throughout the experiment. Further blood samples were collected from all rats at 15 $(100 \mu \mathrm{l}), 30(300 \mu \mathrm{l}), 45(100 \mu \mathrm{l}), 60(300 \mu \mathrm{l})$ and 240 $(100 \mu \mathrm{l}) \mathrm{min}$ following the onset of restraint or respective non-stress period (in control rats). Blood samples were kept on wet ice during the collection, centrifuged $(3200 \mathrm{~g}$ / $10 \mathrm{~min} / 4{ }^{\circ} \mathrm{C}$ ) and plasma stored at $-20{ }^{\circ} \mathrm{C}$. Following collection of the final blood sample at $240 \mathrm{~min}$, rats were decapitated and brains were collected and frozen on dry ice.

\section{Experiment 2: chronic citalopram and acute restraint stress}

Minipumps were implanted into rats on day 0 and on day 11 rats had i.v. and s.c. cannulae fitted as described previously. On day 14, all rats had an initial i.v. blood sample $(300 \mu \mathrm{l})$ collected at time $0 \mathrm{~min}$. Half of the rats fitted with minipumps containing citalopram and half of the vehicle infusion rats were exposed to a 60 minute restraint and the remaining rats were retained in their home cages through the experiment. Subsequent blood samples were collected at 30 and $60 \mathrm{~min}(300 \mu \mathrm{l})$. Blood samples were kept on wet ice during the collection. At $240 \mathrm{~min}$, rats were decapitated and brains were collected and frozen on dry ice.

\section{Radioimmunoassay}

Analysis of the plasma hormones corticosterone and ACTH was undertaken using in house radioimmunoassays (RIA). ACTH peptide was initially extracted from plasma using C18 Sep-Pak cartridges (Millipore, Watford, UK) prior to RIA (Jessop et al. 1989). Plasma concentrations of ACTH were not measured at all time points because of the relatively greater volume of blood required for the ACTH assay. The ACTH assay is specific for ACTH (1-39) in normal rat plasma, as previously determined by high performance liquid chromatography (HPLC) (Jessop et al. 1989). There is no evidence for detection of higher molecular weight forms or smaller pro-opiomelanocortin (POMC) peptide products such as $\alpha-\mathrm{MSH}$. Plasma corticosterone was measured directly from plasma $(5 \mu \mathrm{l}$ in $500 \mu \mathrm{l}$ assay buffer) with antiserum provided by G Makara (Institute of Experimental Medicine, Budapest, Hungary). The corticosterone assay as previously detailed by Harbuz et al. 1992. Intra- and inter- assay variations were all less than $12 \%$.

\section{In situ hybridisation}

Brain slices $(12 \mu \mathrm{m})$ of PVN were prepared using a cryostat (c.f. Figure 27 in Paxinos \& Watson 1998) and mounted onto gelatin-coated slides. Oligo probe in situ hybridization (ISH), as described previously by Harbuz \& Lightman (1989), was used to analyze parvocellular CRF mRNA, parvocellular AVP mRNA and magnocellular OT mRNA in the PVN. The oligo probes have been previously characterized (OT and AVP, Young et al. $1986 a$ and CRF, Young et al. 1986b). The specific activities (d.p.m./mol) of the oligo probes were: experiment 1: CRF $\left(1.54 \times 10^{19}\right)$, AVP $\left(6.71 \times 10^{18}\right)$ and OT $\left(4.53 \times 10^{18}\right)$; experiment 2 : CRF $\left(4.45 \times 10^{18}\right)$, AVP $\left(3 \cdot 30 \times 10^{18}\right)$ and OT $\left(1 \cdot 11 \times 10^{19}\right)$.

\section{Statistics and data analysis}

Data are represented as the mean \pm S.E.M. For radioimmunoassay data a two-way analysis of variance (ANOVA) was used followed by the Fisher's PLSD post-hoc test (Statview 5·0, SAS Institute Inc., NC, USA). For ISH data autoradiographic images (Examples of similar images are shown in Kinoshita et al. 2000) of probe bound to target mRNA were analyzed using an image analysis system (Image NIH 6.12, National Institute of Health, Bethesda, MD, USA) and values were calibrated according to the autoradiographic images of C-14 standards (co-exposed with the samples on the same film). For each rat, two sections of PVN per slide/probe were measured. To distinguish parvocellular AVP from magnocellular AVP mRNA, data was generated using a threshold function as described by Kinoshita et al. (2000). In our previous paper (Kinoshita et al. 2000) we compared the threshold method with the grain-counting method that is more usually applied to studies of the parvocellular AVP system. We were able to demonstrate the effectiveness of the threshold method despite the penumbra of signal surrounding the magnocellular region. Although there is a chance that by increasing the background this may result in increased false negatives, we were able to demonstrate quite subtle differences in signal comparing the two methods. We are entirely confident that a positive result using the threshold technique, because of the potential risk of false negatives, means that any significant changes are 

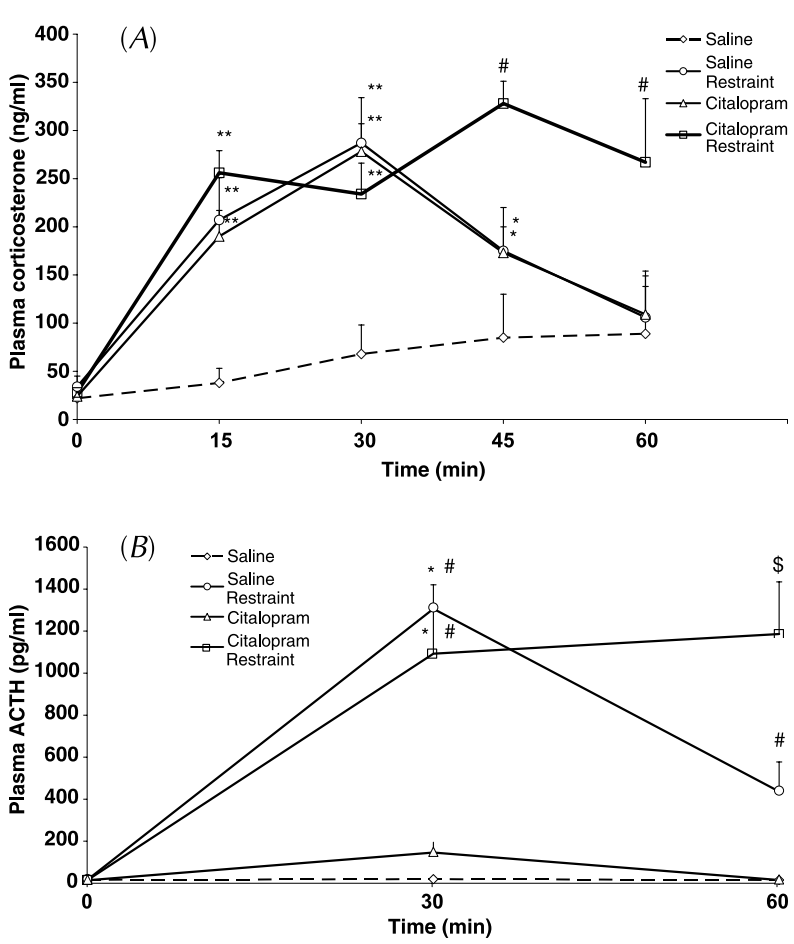

Figure 1 Vehicle or citalopram were administered at time 0 min and i.v. blood samples were collected at the time points shown (time 0 blood samples represent pre-dosing/pre-restraint stress blood samples). Values represent means+s.E. of plasma corticosterone or ACTH $(n=5-7)$ at each time point. $P<0.05$ was considered significant. (A) Plasma corticosterone response to acute restraint following a single injection of citalopram. Significant difference *from time 0 within the same treatment group and from the saline group at each time point, ${ }^{\#}$ compared with all treatment groups and time 0 samples (two-way ANOVA; $F_{23138}=12 \cdot 582$, $P<0.001$, (Fisher's PLSD post-hoc test; ${ }^{\star} P<0 \cdot 05$ and $\left.{ }^{* *}{ }^{*} P<0 \cdot 001\right)$ ). (B) Plasma ACTH response to acute restraint following a single injection of citalopram. Significant difference * compared with time 0 within the same treatment group, ${ }^{\#}$ compared with saline group, $\$$ compared with time 0, and all groups at 60 min (two-way ANOVA; $F_{11,63}=11 \cdot 741, P<0 \cdot 001$ (Fisher's PLSD post-hoc test; ${ }^{\#} P<0.05$ and $\left.\left.{ }^{*} \$ P<0 \cdot 001\right)\right)$.

likely to be physiologically relevant. ISH data was statistically compared using one-way ANOVA followed by Fisher's PLSD post hoc test. ISH data is presented as a percentage of the saline control group.

\section{Results}

\section{Experiment 1}

Corticosterone data Basal levels of corticosterone were $35 \pm 10 \mathrm{ng} / \mathrm{ml}$ prior to drug administration and restraint and these levels did not alter significantly within the saline control group throughout the experiment (Fig. 1A). In saline treated rats, restraint stress was able to induce significant elevations in plasma corticosterone between 15 and $45 \mathrm{~min}$ into the $60 \mathrm{~min}$ restraint procedure compared with saline treated control rats. A single s.c. injection of $5 \mathrm{mg} / \mathrm{kg}$ citalopram was able to significantly increase plasma corticosterone levels in non-restrained rats from 15 min following administration until 45 min compared with saline control rats, with levels comparable to those in saline treated restrained rats. In the combined citalopram and restraint treatment group, citalopram induced a prolonged corticosterone response to restraint stress with corticosterone levels remaining significantly increased compared with non-stressed controls, citalopram treated and saline treated restrained rats at 45 and $60 \mathrm{~min}$. Corticosterone levels returned to basal levels in all groups by $240 \mathrm{~min}$.

ACTH data Basal levels of ACTH in plasma prior to drug administration were $14 \pm 2 \mathrm{pg} / \mathrm{ml}$ and these levels remained constant throughout the experiment in the saline control group (Fig 1B). ACTH was significantly increased in saline treated restrained rats compared with saline treated control rats. Citalopram alone was not found to significantly elevate plasma ACTH levels at $30 \mathrm{~min}$ following administration of drug. However, citalopram treated restrained rats had significantly elevated levels of $\mathrm{ACTH}$ at $30 \mathrm{~min}$ and these levels remained elevated at $60 \mathrm{~min}$.

mRNA data Brains were collected and frozen $4 \mathrm{~h}$ after the start of the experiment on the sample day, therefore all mRNA data is representative of this time point. Parvocellular AVP mRNA was not significantly altered by citalopram treatment or by acute restraint stress. However, in the combined treatment group AVP mRNA was significantly enhanced in the pPVN (Fig. 2A). Parvocellular CRF mRNA was significantly enhanced by restraint and by the combined treatment but was unaffected by acute citalopram treatment (Fig. 2B). Magnocellular OT mRNA was enhanced by restraint or citalopram, with no enhanced effects resulting from the combined treatment (Fig. 2C).

\section{Experiment 2}

Corticosterone data Chronic administration of citalopram $(10 \mathrm{mg} / \mathrm{kg} /$ day $)$ for 14 days did not affect the basal levels of corticosterone $(35 \pm 10 \mathrm{ng} / \mathrm{ml})$ and there were no significant differences in corticosterone levels, in any of the rats, prior to restraint on day 14 (Fig. 3A). Neither saline nor citalopram infusion altered basal levels of corticosterone throughout the experiment. Restraint stress increased plasma corticosterone levels in saline treated rats and the corticosterone response to acute restraint stress was not affected by chronic citalopram treatment.

ACTH data Chronic administration of citalopram $(10 \mathrm{mg} / \mathrm{kg} /$ day $)$ for 14 days did not affect the basal levels 

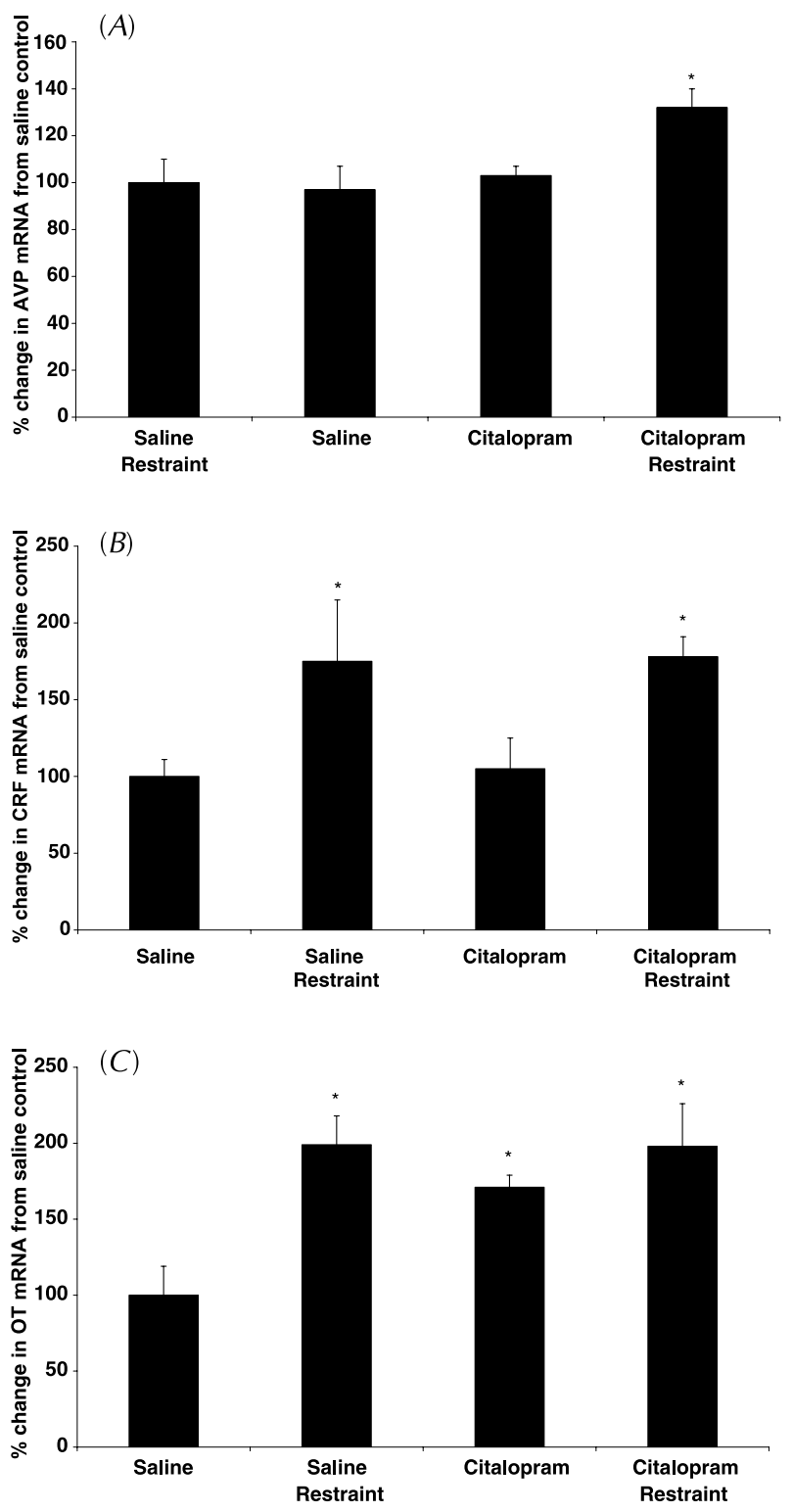

Figure 2 Vehicle or citalopram were administered $4 \mathrm{~h}$ prior to decapitation and brain removal for in situ hybridisation analysis of arginine vasopressin (AVP), corticotrophin releasing factor (CRF) and oxytocin (OT) mRNA. Values represent the means+s.E. of percentage increase compared with saline control (designated at $100 \%)(n=5-8) . P<0 \cdot 05$ was considered significant. (A) AVP mRNA response to acute restraint following a single injection of citalopram. *Significant difference compared with all other groups (one-way ANOVA; $F_{3,22}=5 \cdot 448, P<0 \cdot 05$ (Fisher's PLSD post-hoc test $P<0 \cdot 05)$ ). (B) CRF mRNA response to acute restraint following a single injection of citalopram. *Significant increase compared with saline and citalopram control groups (one-way ANOVA; $F_{3,22}=4.497, P<0.05$ (Fisher's PLSD post-hoc test; $\left.P<0.05\right)$ ). (C) OT mRNA response to acute restraint following a single injection of citalopram. *Significant difference compared with the saline control group (one-way ANOVA; $F_{3,24}=5 \cdot 144, P<0 \cdot 05$ (Fisher's PLSD post-hoc test $P<0 \cdot 05)$ ).
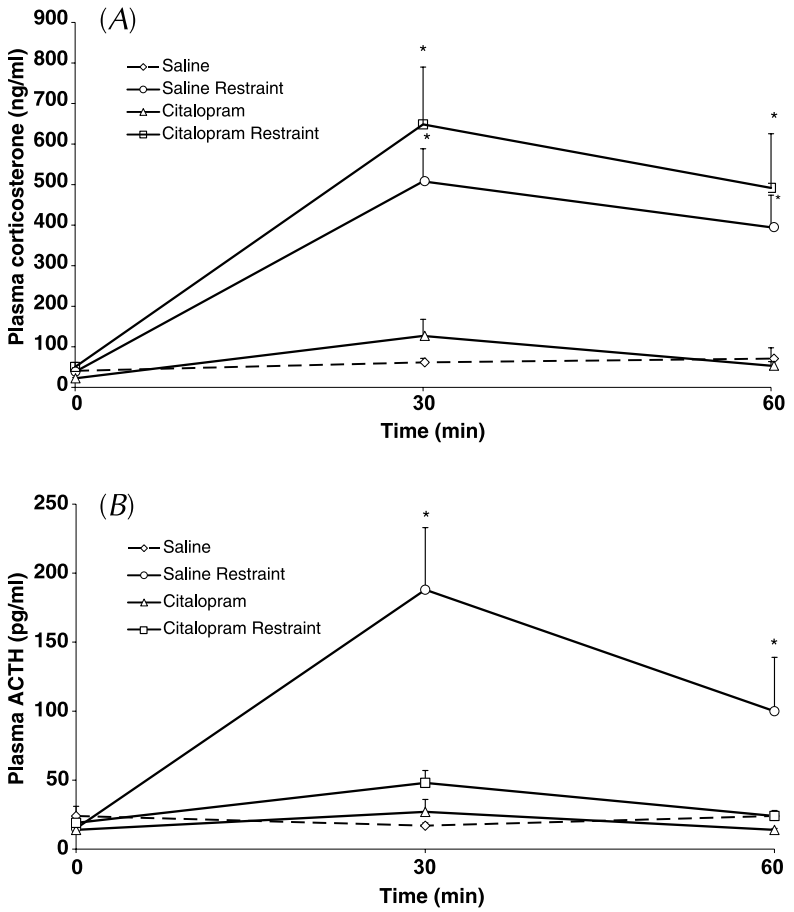

Figure 3 Vehicle or citalopram were infused via minipumps (s.c.) for 14 days. On day 14 i.v. blood samples were collected at the time points shown relative to the start of an hour restraint at time 0 (blood samples collected prior to the start of restraint are represented as 0 minute samples). Values represent means + S.E. of plasma corticosterone or ACTH $(n=7) . P<0 \cdot 05$ was considered significant. (A) Plasma corticosterone response to acute restraint following chronic citalopram infusion. * Significant increase compared with time 0 and to control groups at 30 and $60 \mathrm{~min}$ (two-way ANOVA; $F_{11,67}=11.851, P<0.001$ (Fisher's PLSD post-hoc test $P<0 \cdot 001)$ ). (B) Plasma ACTH response to acute restraint following chronic citalopram infusion. *Significant increase compared with time 0 , control groups and to the citalopram restraint group (two-way ANOVA; $F_{11,68}=3.347, P<0.001$ (Fisher's PLSD post-hoc test ${ }^{\#} P<0.05$ and $\left.\left.{ }^{*} P<0 \cdot 001\right)\right)$.

of ACTH $(18 \pm 6 \mathrm{pg} / \mathrm{ml})$ and there were no significant differences in ACTH levels, in any of the rats, prior to restraint on day 14 (Fig. 3B). Basal levels of ACTH were maintained in the saline and citalopram control groups throughout the experiment. Restraint stress increased plasma ACTH levels in saline treated rats. However, the ACTH response to restraint was suppressed at $30 \mathrm{~min}$ in rats treated for 14 days with citalopram.

mRNA data Brains were collected $4 \mathrm{~h}$ after the start of the study on the sample collection day, therefore all mRNA data is representative of this time point. AVP mRNA was increased in the pPVN in rats following 14 days of citalopram infusion and in the citalopram-restraint group compared with saline infused controls (Fig. 4A). Restraint stress did not alter AVP mRNA levels compared with their saline controls. CRF mRNA was significantly 

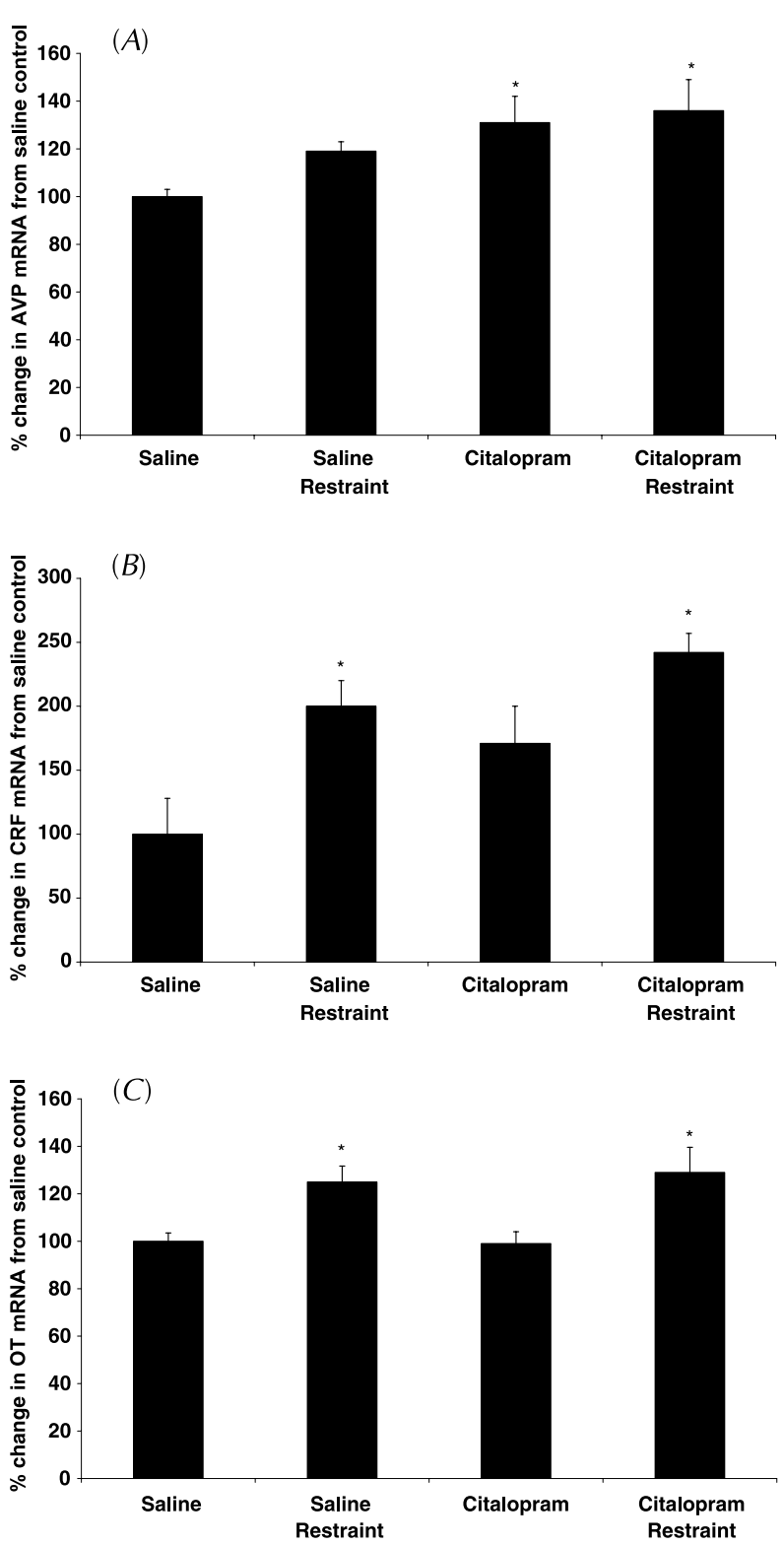

Figure 4 Vehicle or citalopram were administered via minipumps (s.c.). On day 14 , rats were decapitated and brains were collected $4 \mathrm{~h}$ after the start of an hour restraint for in situ hybridisation analysis of arginine vasopressin (AVP), corticotrophin releasing factor (CRF) and oxytocin (OT) mRNA. Values represent the means+s.E. of percentage change compared with saline control (designated as $100 \%)(n=5-8) . P<0.05$ was considered significant. (A) AVP mRNA response to acute restraint following chronic infusion of citalopram. *Significant increase compared with the saline control group (one-way ANOVA; $F_{3,21}=3 \cdot 470, P<0.05$ (Fisher's PLSD post-hoc test $P<0 \cdot 05)$ ). (B) CRF mRNA response to acute restraint following chronic infusion of citalopram. *Significant increase compared with the saline control group (one-way ANOVA; $F_{3,21}=4 \cdot 683, P<0.05$ (Fisher's PLSD post-hoc test $P<0 \cdot 05)$ ). (C) OT mRNA response to acute restraint following chronic infusion of citalopram. *Significant increase compared with saline and citalopram control groups (one-way ANOVA;

$F_{3,19}=5 \cdot 695, P<0.05$ (Fisher's PLSD post-hoc test $P<0 \cdot 05$ )). increased by restraint stress in saline infused rats. Chronic citalopram treatment did not enhance basal CRF mRNA compared with saline infused controls nor did it alter the CRF mRNA response to restraint as there was no significant difference between saline-restraint and citalopram-restraint rats (Fig. 4B). Magnocellular OT mRNA was enhanced by acute restraint stress in both saline-infused and citalopram-infused rats (Fig. 4C). Chronic citalopram alone had no effect on OT mRNA.

\section{Discussion}

We have confirmed previous studies that have reported an increase in plasma ACTH and corticosterone in response to acute citalopram treatment in rats (Jensen et al. 1999). These data have extended these observations to demonstrate a prolonged $\mathrm{ACTH}$ and corticosterone response to acute restraint stress following a single injection of citalopram. A vasopressinergic mechanism may be involved in the citalopram-induced prolonged hormone response to acute restraint, as there was a significant increase in AVP mRNA in the pPVN following combined treatment with citalopram and restraint, compared with either treatment alone. In contrast, there was no further increase in CRF mRNA induced by the combined treatment, compared with restraint stress alone. It is unlikely that citalopram has a direct action on the PVN neurons themselves, as citalopram alone was unable to evoke an increase in CRF mRNA. It is therefore likely that citalopram was acting to enhance the release of serotonin in response to restraint stress and this may have altered AVP levels in the pPVN. Chronic citalopram infusion unlike acute citalopram treatment did not alter baseline hormone levels when given by minipump. Chronic citalopram treated, infused over 14 days, prevented the ACTH response, yet had no effect on the corticosterone response, to acute restraint stress. At the hypothalamic level, there was an increase in AVP mRNA in the pPVN associated with chronic citalopram infusion suggesting a stimulatory action of citalopram on AVP-containing CRF neurons.

Plasma corticosterone and ACTH were transiently increased in rats in response to acute restraint stress as demonstrated previously (Harbuz et al. 1993, Viau et al. 1993, Harbuz et al. 1994). A single injection of citalopram $(5 \mathrm{mg} / \mathrm{kg})$ increased plasma levels of corticosterone as shown by Jensen et al. (1999) using a higher dose $(10 \mathrm{mg} / \mathrm{kg})$ of citalopram. At $5 \mathrm{mg} / \mathrm{kg}$, citalopram was able to elevate basal plasma corticosterone to comparable levels induced by restraint stress. However, at $5 \mathrm{mg} / \mathrm{kg}$, citalopram had no effect on plasma ACTH, at least at the 30 minute time point in 'non-stressed' rats. This would suggest that ACTH release, in response to $5 \mathrm{mg} / \mathrm{kg}$ citalopram, has either a response with a shorter duration or exhibits a response with lower amplitude than that stimulated by $10 \mathrm{mg} / \mathrm{kg}$ of citalopram. The dose of citalopram 
used in this study $(5 \mathrm{mg} / \mathrm{kg})$ was chosen to prevent maximal stimulation of the HPA axis by citalopram, in order that a combined response to restraint and citalopram could be clearly distinguished from solo treatments. At this dose $(5 \mathrm{mg} / \mathrm{kg})$, citalopram was not found to further enhance the levels of corticosterone induced by restraint stress (during the peak restraint-induced stimulation of corticosterone), but was found to prolong the increase in plasma corticosterone induced by restraint stress. The combined action of citalopram and restraint stress also resulted in sustained increases in ACTH.

Parvocellular AVP mRNA was not induced by acute restraint stress alone. It has previously been reported that increases in AVP mRNA in response to restraint stress are strain dependent with CFY rats but not Sprague-Dawley rats having an increase in AVP mRNA in the pPVN (Harbuz et al. 1994). AVP was also not affected by a single injection of citalopram when given alone, but the combined treatment of restraint and citalopram did enhance AVP mRNA in the pPVN. Therefore citalopram may be able to prolong the acute corticosterone and ACTH response to restraint via an AVP-mediated pathway, which would be an interesting consideration for future studies. The possibility that citalopram when combined with restraint is able to stimulate AVP-associated pathways is intriguing due to the hypothesis that under chronic stimulatory conditions AVP can become the dominant PVN neuropeptide regulating the HPA axis (Aquilera 1994, Harbuz 2002).

Paraventricular OT mRNA was increased in both restrained and citalopram treated rats which may reflect enhanced plasma OT levels following a single dose of an SSRI (Uvnas-Moberg et al. 1999) and in both plasma and the PVN, following exposure to acute stress (Neumann 2002). The combined treatment of restraint and citalopram was however not able to further enhance OT mRNA in the PVN. OT is proposed to have a complex interaction with the HPA axis that varies under basal and stressed conditions. It is claimed that OT may increase the ACTH response to various acute stressors (Neumann et al. $2000 a$ ) and may have a potential role in the long term mediation of the HPA axis following withdrawal of a stressor (Nakashima et al. 2002). Conversely, OT may also provide a basal HPA axis regulatory or inhibitory role in rodents (Neumann et al. 2000b). However, Nakashima et al. (2002) found that the intracerebral injection of an OT receptor antagonist did not alter the plasma ACTH level at the end of a single stress. Rather, it presented an effect 2 days after the withdrawal of a single immobilisation stress, suggesting a more involved role for AVP, over OT, in this immediate prolonged activation of the HPA axis evoked by the combined treatment of restraint stress and citalopram. It would seem that OT can provide a homeostatic cue to stimulate or regulate the activity of the axis depending on the level of HPA axis stimulation.
Plasma OT levels have previously been shown to be increased by chronic citalopram treatment (Uvnas-Moberg et al. 1999) however, our data demonstrates that OT mRNA levels were not increased by chronic citalopram as they had been for acute citalopram. This would suggest that paraventricular OT mRNA increases are only induced during early SSRI treatment and increased plasma levels of OT are seen during the early to mid-phase of SSRI treatment. This elevation in plasma OT may aid the SSRI-induced modulations that are involved in the therapeutic action of these antidepressants.

Chronic infusion of citalopram for 14 days, did not alter basal plasma corticosterone or ACTH levels on day 14 under non-stressed conditions confirming previous data (Jensen et al. 1999). The corticosterone response to acute restraint stress was unaffected by chronic citalopram treatment. However, the ACTH response was suppressed in rats treated chronically with citalopram. This apparent lack of ACTH response at $30 \mathrm{~min}$ despite a corticosterone response to restraint in rodents exposed to citalopram for 14 days may indicate that the adrenal glands of rats treated chronically with citalopram may be sensitive to low levels of ACTH, an observation which needs to be confirmed. Reports of dissociations between plasma ACTH and corticosterone concentrations are not uncommon in the literature (Dohanics et al. 1990, Larsen et al. 1994, Dallman et al. 2002), but these dissociations have not been systematically investigated, to our knowledge, to date. Such studies, including those that may consider the potential dissociation between cortisol and ACTH in depressed patients treated with SSRIs would be of considerable interest and would be worthy of further study.

Infusion of citalopram for 14 days increased parvocellular AVP mRNA but not parvocellular CRF mRNA suggesting that citalopram may be working through a vasopressinergic mechanism in these rats. CRF mRNA may have initially been enhanced during the early stages of SSRI treatment, as demonstrated by Wieczorek et al., (2001). Our data demonstrate a slight but non-significant increase in CRF mRNA in the PVN of citalopram treated rats compared with saline controls, suggesting that the CRF mRNA response to citalopram is attenuated following prolonged exposure, but that AVP mRNA expression is enhanced. This potential switch in the regulatory mechanism of the HPA axis, by citalopram, may be critical for the clinical effectiveness of SSRI treatment. Although our data provide evidence for an involvement of AVP, this evidence is on the basis of changes in AVP mRNA and not peptide release. Further studies would be required to confirm this possibility. An increase in AVP has been noted in depression (Scott \& Dinan 2002) and this may contribute to anxiety-related or depressive symptoms in patients as antagonists for the $\mathrm{V}_{1 \mathrm{~b}}$ receptor have been shown to have potential antidepressant and anxiolytic effects in rodents (Serradeil-Le Gal et al. 2003, Wigger et al. 2004). 
Although we have reported a SSRI-induced increase in parvocellular AVP mRNA, SSRIs have been reported to reduce the vasopressin hyper-drive in high-anxiety bred rats (Keck et al. 2003). SSRIs may therefore target the vasopressin system to normalise the ratio of CRF to AVP and re-establish $\mathrm{CRF}_{\mathrm{R} 1}$ function at the pituitary level in depressed patients. However, in 'non-depressed' rats, the SSRI-induced increase in AVP during chronic treatment may represent an alternate SSRI-mediated event that may contribute to an alteration in the way the HPA axis is able to respond to acute stress.

It is generally recognized that in response to repeated/ chronic stress AVP is critical in sustaining corticotroph responsiveness in the presence of elevated blood glucocorticoid levels and that this is reflected by an increase in AVP receptors (Aguilera \& Rabadan-Diehl 2000). In adjuvantinduced arthritis it has been shown that CRF mRNA is decreased, while AVP mRNA is increased in the pPVN in the face of increased levels of plasma corticosterone and that these changes are reflected by similar changes in mature CRF and AVP peptide release into the hypophysial portal blood (Chowdrey et al. 1995). There is also evidence that various stress paradigms can induce increases in AVP mRNA and heteronuclear RNA (hnRNA), despite the increase in circulating levels of glucocorticoids (Aguilera \& Rabadan-Diehl 2000). Cumulatively, these data suggest that in response to repeated/chronic stress AVP may be a more important regulator of the HPA axis than CRF. Our findings of a preferential action on AVP mRNA suggests SSRIs may operate through such a mechanism.

In conclusion, we have demonstrated that acute and chronic SSRI treatment can impact on the rodent response to acute restraint stress. This would suggest that the HPA axis is affected by SSRI treatments, and that there may be potential involvement of the vasopressin-containing subset of CRF neurons in the pPVN.

\section{Acknowledgements}

This work was carried out in collaboration with $\mathrm{H}$ Lundbeck A/S, Copenhagen, Denmark. The authors declare that there is no conflict of interest that would prejudice the impartiality of this scientific research.

\section{Funding}

The work carried out in this paper was funded by the MRC and H Lundbeck A/S, Copenhagen, Denmark.

\section{References}

Aguilera G 1994 Regulation of pituitary ACTH secretion during chronic stress. Frontiers in Neuroendocrinology 15 321-350.
Aguilera G \& Rabadan-Diehl C 2000 Vasopressinergic regulation of the hypothalamic-pituitary-adrenal axis: implications for stress adaptation. Regulatory Peptides 96 23-29.

Arborelius L, Owens M, Plotsky P \& Nemeroff C 1999 The role of corticotrophin-releasing factor in depression and anxiety disorders. Journal of Endocrinology 160 1-12.

Aubury J, Bartanusz D, Jesova D, Belin D \& Kiss J 1999 Single stress induces long lasting elevations in vasopressin mRNA levels in CRF hypophysiotrophic neurons, but repeated stress is required to modify AVP immunoreactivity. Journal of Neuroendocrinology 11 337-384.

Buckingham J, Cowell A, Gillies G, Herbison A \& Steel J 1997 The neuroendocrine system: anatomy, physiology and responses to stress. In Stress and Stress Hormones and the Immune System, pp 10-47. Eds J Buckingham, A Cowell \& G Gillies. London: John Wiley and Sons.

Chaouloff F 2000 Serotonin, stress and corticoids. Journal of Psychopharmacology 14 139-151.

Chowdrey H, Larsen P, Harbuz M, Jessop D, Aguilera G, Eckland D \& Lightman S 1995 Evidence for arginine vasopressin as the primary activator of the HPA axis during adjuvant-induced arthritis. British Journal of Pharmacology 116 2417-2424.

Dallman M, Akana S, Schribner K, Bradbury M, Walker C, Strack A \& Cascio C 1991 Stress, feedback and facilitation in the hypothalamo-pituitary-adrenal axis. Journal of Neuroendocrinology 4 517-526.

Dallman M, Viau V, Bhatnagar S, Gomez F, Laugero K \& Bell M 2002 Corticotropin-releasing factor, corticosteroids, stress and sugar: energy balance, the brain and behavior. Hormones, Brain and Behavior 571-603.

Davis L, Yonkers K, Trivedi M, Kramer G \& Petty F 1999 The mechanism of action of SSRI's: a new hypothesis. In Selective serotonin reuptake inhibitors: Past, present and future. pp 181-182. Ed SC Stanford. London: University College.

De Bellis M, Gold P, Geractioti T, Listwak S \& Kling M 1993 Association of Fluoxetine treatment with reduced CSF concentration of CRF and AVP in patients with major depression. American Journal of Psychiatry 150 656-657.

De Kloet E, Vreugdenhil E, Oitzl M \& Joels M 1998 Brain corticosteroid receptor balance in health and disease. Endocrine Reviews 19 269-301.

Dinan T 1996. Serotonin and the regulation of the hypothalamicpituitary-adrenal axis function. Life Sciences 58 1683-1694.

Dohanics J, Kovacs K, Folly G \& Makara G 1990 Long-term salt loading impairs pituitary responsiveness to ACTH secretagogues and stress in rats. Peptides 11 59-63.

Gibbons L 1964. Cortisol secretion rate in depressive illness. Archives of General Psychiatry 10 572-575.

Gillies G, Linton E \& Lowry P 1982 Corticotrophin-releasing activity of the new CRF is potentiated several times by vasopressin. Nature 299 355-357.

Graeff F, Guimaraes F, Andrade T \& Deakin J 1996 Role of 5HT in stress, anxiety and depression. Pharmacology Biochemistry and Behaviour 54 129-141.

Harbuz M 2002 Neuroendocrinology of autoimmunity. International Review of Neurobiology 52 133-161.

Harbuz M \& Lightman S 1989 Responses of the hypothalamic and pituitary mRNA to physical and psychological stress in the rat. Journal of Endocrinology 122 705-711.

Harbuz M \& Lightman S 1992 Stress and the hypothalamo-pituitaryadrenal axis: acute, chronic and immunological activation. Journal of Endocrinology 134 327-339.

Harbuz MS, Rees RG, Eckland D, Jessop DS, Brewerton D \& Lightman S 1992 Paradoxical responses of hypothalamic corticotropin-releasing factor (CRF) messenger ribonucleic acid (mRNA) and CRF-41 peptide and adenohypophysial proopiomelanocortin mRNA during chronic inflammatory stress. Endocrinology 130 1394-1400. 
Harbuz M, Chalmers J, De Souza L \& Lightman S 1993 Stress-induced activation of CRF and C-fos mRNAs in the paraventricular nucleus are not affected by serotonin depletion. Brain Research 609 167-173.

Harbuz M, Jessop D, Lightman S \& Chowdry H 1994 The effects of restraint of hypertonic saline stress on corticotrophin-releasing factor, arginine vasopressin and proenkephalin A mRNA's in the CFY, Sprague-Dawley and Wistar rats. Brain Research 667 6-12.

Hatzinger M 2000 Neuropeptides and the hypothalamic-pituitaryardrenocortical (HPA) system: review of recent research strategies in depression. World Journal of Biological Psychiatry 1 105-111.

Herman J, Cullinan W, Ziegler D \& Tasker J 2002 Role of the paraventricular nucleus microenvironment in stress regulation. European Journal of Neuroscience 1 381-385.

Jensen J, Jessop D, Harbuz M, Mork A, Sanchez C \& Mikkelsen J 1999 Acute and long-term treatments with the selective serotonin inhibitor citalopram modulates the HPA axis activity at different levels in male rats. Journal of Neuroendocrinology 11 465-471.

Jensen J, Mork A \& Mikkelsen J 2001 Chronic antidepressant treatments decrease pro-opiomelanocortin mRNA expression in the pituitary gland: Effects of acute stress and 5HT1A receptor activation. Journal of Neuroendocrinology 13 887-893.

Jessop D, Eckland D, Todd K \& Lightman S 1989 Osmotic regulation of hypothalamo-neurointermediate lobe corticotrophin-releasingfactor-41 in the rat. Journal of Endocrinology 120 119-124.

Jorgensen H, Knigge U, Kjaer A, Moller M \& Warberg J 2002 Serotonergic stimulation of corticotrophin-releasing hormone and pro-opiomelanocortin gene expression. Journal of Neuroendocrinology $14788-795$.

Jorgensen H, Knigge U, Kjaer A, Vadsholt T \& Warberg J 1998 Serotonergic involvement in stress-induced ACTH release. Brain Research 811 10-20.

Keck M, Welt T, Muller M, Uhr M, Ohl F, Wigger A, Toschi N, Holsboer F \& Landgraf R 2003 Reduction of hypothalamic vasopressinergic hyperdrive contributes to clinically relevant behavioural and neuroendocrine effects of chronic paroxetine treatment in a psychopathological rat model. Neuropsychopharmacology 28 235-243.

Kinoshita H, Jessop D, Finn D \& Harbuz M 2000 Cyanamideinduced activation of the hypothalamo-pituitary-adrenal axis. Journal of Neuroendocrinology 12 255-262.

Larsen P, Mikkelsen J, Jessop D, Lightman S \& Chowdrey H 1994 Neonatal monosodium glutamate treatment alters both the activity and the sensitivity of the rat hypothalamo-pituitary-adrenocortical axis. Journal of Endocrinology 141 497-503.

Maes M, Meltzer Y, D’Hondt P, Cosyns P \& Blockx P 1995 Effects of serotonin precursors on the negative feedback effects of glucocorticoids on hypothalamic-pituitary-adrenal axis function in depression. Psychoneuroendocrinology 20 149-167.

Massand P \& Gupta S 1999 Selective serotonin reuptake inhibitors: An update. Harvard Review of Psychiatry 7 69-84.

Matheson K, Knowles A, Guthrie D, Cage D, Weinzapfel D \& Blackbourne J 1997 Actions of serotonergic agents on hypothalamic-pituitary-adrenal axis activity in the rat. General Pharmacology 29 823-828.

Nakashima T, Noguchi T, Furukawa T, Yamasaki M, Makino S, Miyata S \& Kiyohara T 2002 Brian oxytocin augments stress-induced long-lasting plasma adrenocorticotrophic hormone elevation in rats. Neuroscience Letters 321 161-164.

Nemeroff C, Winderlov E, Bissette G, Walleus H, Karlsson I, Eklund K, Kilts C, Loosen P \& Vale W 1984 Elevated concentration of CSF CRF immunoreactivity in depressed patients. Science $\mathbf{2 2 6}$ $1342-1344$

Neumann I 2002 Involvement of the brain oxytocin system in stress coping: interactions with the hypothalamo-pituitary-adrenal axis. Progress in Brain Research 139 147-162.
Neumann I, Kromer S, Toschi N \& Ebner K 2000a Brain oxytocin inhibits the (re)activity of the hypothalamo-pituitary-adrenal axis in male rats: involvement of hypothalamic and limbic brain regions. Regulatory Peptides 96 31-38

Neumann I, Wigger A, Torner L, Holsboer F \& Landgraf R 2000 b Brian oxytocin inhibits basal and stress-induced activity of the hypothalamo-pituitary-adrenal axis in male and female rats: Partial action within the paraventricular nucleus. Journal of Neuroendocrinology 12 235-243.

Pare W \& Glavin G 1986 Restraint stress in biomedical research: a review. Neuroscience Biobehaviour 10 339-370.

Pariante C, Thomas S, Lovestone S, Makoff A \& Kerwin R 2004 Do antidepressants regulate how cortisol affects the brain? Psychoneuroendocrinology 29 423-447.

Paxinos G \& Watson C 1998 The Rat Brain in stereotaxic coordinates, edn 4. London: Academic Press Ltd.

Raap D \& Van de Kar L 1999 Selective serotonin re-uptake inhibitors and neuroendocrine function. Life Sciences 65 1217-1235.

Ratka A, Sutanto W, Bloemers M \& De Kloet E 1989 On the role of brain mineralocorticoid (type 1) and glucocorticoid (type 2) receptors in neuroendocrine regulation. Neuroendocrinology $\mathbf{5 0}$ $117-123$.

Reul J \& De Kloet E 1985 Two receptor systems for corticosterone on the electrophysiology of hippocampal CA1 pyramidal cells in vitro. Brain Research Bulletin 12 349-353.

Scaccianoce S, Muscolo LA, Cigliana G, Navarra D, Nicolai R \& Angelucci L 1991 Evidence for a specific role of vasopressin in sustaining pituitary-adrenocortical stress response in the rat. Endocrinology 128 3138-3143.

Scott L \& Dinan T 2002 Vasopressin as a target for antidepressant development: an assessment of the available evidence. Journal of Affective Disorders 72 113-124.

Serradeil-Le Gal C, Derick S, Brossard G, Manning M, Simiand J, Gaillard R, Griebel G \& Guillon G 2003 Functional and pharmacological characterization of the first specific agonist and antagonist for the V1b receptor in mammals. Stress 6 199-206.

Swanson L \& Sawchenko P 1983 Hypothalamic integration: organization of the paraventricular and supraoptic nuclei. Annual Review of Neuroscience 6 269-324.

Uvnas-Moberg K, Bjjorkstrand E, Hillegaart V \& Ahlenius S 1999 Oxytocin as a possible mediator of SSRI-induced antidepressant effects. Psychopharmacology 142 95-101.

Viau V, Sharma S, Plotsky P \& Meaney M 1993 Increased plasma ACTH responses to stress in nonhandled compared with handled rats require basal levels of corticosterone and are associated with increased levels of ACTH secretagogues in the median eminence. Journal of Neuroscience 13 1097-1105.

Whitnall M \& Gainer H 1988 Major pro-vasopressin-expressing and pro-vasopressin-deficient subpopulations of corticotrophin-releasing hornone neurons in normal rats. Neuroendocrinology 47 176-180.

Wieczorek I, Schulz C, Jarry H \& Lehnert H 2001 The effects of the selective serotonin reuptake inhibitor fluvoxamine on body weight in zucker rats are mediated by corticotrophin-releasing hormone. International Journal of Obesity Related Metabolic disorders $\mathbf{2 5}$ 1566-1569.

Wigger A, Sanchez M, Mathys K, Ebner K, Frank E, Liu D, Kresse A, Neumann I, Holsboer F, Plotsky P \& Landgraf R 2004 Alterations in central neuropeptide expression, release and receptor binding in rats bred for high anxiety: critical role of vasopressin. Neuropsychopharmacology 1 1-14.

Young E, Haskett R, Murphy-Weinberg V, Watson S \& Axil H 1991 Loss of fast-feedback in depression. Archives of General Psychiatry 48 693-699.

Young E \& Vazquez D 1996 Hypercortisolemia, hippocampal glucocorticoid receptors and fast feedback. Molecular Psychiatry 1 149-159. 
Young W III, Mezey E \& Siegel R 1986a Vasopressin and oxytocin mRNAs in adrenalectomized and Brattleboro rats: analysis by quantitative in situ hybridization histochemistry. Brain Research 387 231-241.

Young W III, Mezey E \& Siegel R $1986 b$ Quantitative in situ hybridization histochemistry reveals increased levels of corticotropin-releasing factor mRNA after adrenalectomy in rats. Neuroscience Letters 70 198-203.

Received 11 March 2005

Accepted 24 March 2005 